\title{
Tiomolibdate Diammonium
}

National Cancer Institute

\section{Source}

National Cancer Institute. Tiomolibdate Diammonium. NCI Thesaurus. Code C74001.

An ammonium salt with potential antiang iog enic and antitumor activities.

Tetrathiomolybdate has been found to deplete systemic copper reserves through an unknown mechanism. This agent has been shown to inhibit the activities of cuproenzymes, including superoxide dismutase 1 (SOD1) and cytochrome c oxidase (COX), which may contribute to its antiang iogenic and antitumor effects. 